\title{
Case report: papillitis as the sole ocular sign in Lyme disease
}

\section{Katherine McVeigh Georgios Vakros}

Department of Ophthalmology, Raigmore Hospital, Inverness, United Kingdom
Correspondence: Georgios Vakros 28 Ashgrove Avenue, AB25 3BQ, Aberdeen, United Kingdom Tel +44 7791278717

Email g.vakros.05@aberdeen.ac.uk
This article was published in the following Dove Press journal:

Clinical Ophthalmology

13 July 2012

Number of times this article has been viewed

Background: Lyme disease is a spirochetal disease responsible for a multitude of ocular and systemic manifestations, and patients may present to ophthalmologists and general clinicians with a wide variety of generalized and ocular signs which can result in chronic and disabling sequelae. Here we report two cases of patients suffering with Lyme disease who developed a rare associated papillitis.

Methods: A 48-year-old Scottish man presented with diminished visual acuity, painful ocular eye movements, photophobia, and mild ataxia. Fundus examination revealed bilateral disc swelling with associated hemorrhages in the right eye. Following exclusion of raised intracranial pressure as the cause of the findings, enzyme-linked immunosorbent assay and Western blot serology confirmed a positive result for Borrelia burgdorferi which, along with ophthalmic signs and exposure to an endemic area, confirmed the diagnosis of Lyme disease. A 79-yearold gentleman presented with intermittent short-duration "gray film" in his left eye. Fundus examination revealed left optic disc swelling. He was positive for Lyme's serology and his condition was treated with 2 weeks of intravenous ceftriaxone.

Results: The first patient's inflammation resolved and visual acuity returned to normal following a course of high-dose steroids and intravenous ceftriaxone, followed by oral doxycycline. The second patient's condition improved with high-dose intravenous ceftriaxone.

Conclusion: These patients highlight the fact that Lyme disease should be considered as a differential diagnosis for patients presenting with papillitis. With the incidence of this disease rising and more cases being reported, practitioners in Lyme-endemic areas need to be aware of the various manifestations so that appropriate referrals for treatment can be made.

Keywords: Lyme disease, ocular papillitis, Borrelia burgdorferi

\section{Introduction}

Lyme disease is a tick-borne multisystem disorder resulting from transmission of the spirochete Borrelia burgdorferi. ${ }^{1}$ There is wide variation of potential presenting features of the disease including dermatological, musculoskeletal, cardiovascular, nervous, and ophthalmic manifestations which complicate the diagnosis, ${ }^{2}$ and because of the pathological mimicry, the disease frequently remains undiagnosed and untreated. ${ }^{3}$ Numerous ocular manifestations, including conjunctivitis, periorbital edema, iridocyclitis, vitritis, choroiditis, panophthalmitis, exudative retinal detachment, retinal vasculitis, macular edema, papilledema, optic neuritis, motility abnormalities, stromal keratitis, episcleritis, symblepharon, and orbital myositis have been reported. ${ }^{4}$ However, Lyme disease progresses in three stages, and ophthalmic manifestations present in two thirds of patients at the second stage. ${ }^{5}$ 
Lyme disease is a condition endemic in the highlands of Scotland, hence a clinician should suspect Lyme disease when a patient who has been exposed to such a rural area, presents with ocular and/or vague systemic signs and symptoms. There is limited literature available regarding papillitis as an isolated ocular presentation of Lyme disease in the absence of raised intracranial pressure. Here we discuss two patients diagnosed with Lyme disease who presented to Raigmore Hospital, Inverness, Scotland.

\section{Case report I}

A 48-year-old man presented in November 2009 with decreased visual acuity, painful ocular movements, photophobia, and inferotemporal visual distortion. This was associated with mild ataxia and a nine-day history of a severe, dull, frontal headache, not worsened by the Valsalva maneuver. He had no past ocular history and his medical history consisted of sciatica and psoriasis. Ocular examination revealed decreased visual acuity of 6/24 OD and 6/6 OS. Dilated fundus examination revealed an isolated finding of bilateral optic disc swelling (right more than the left) with associated splinter hemorrhages on the right (Figure 1). There was no evidence of restriction in ocular motility, such as 6th nerve palsy which is a known false localizing sign for raised intracranial pressure, nor was there any other cranial nerve palsy identified. Reliable Humphrey visual field tests showed bilateral diffuse field loss.

Following admission under the medical team for presumed raised intracranial pressure, $\beta$-blockers were commenced to relieve the headache, and radiological and hematological tests were performed. Chest $\mathrm{x}$-ray and computed tomography were inconclusive. Magnetic resonance imaging of the head and orbits showed only nonspecific changes that did not appear to be of clinical significance. Ventricles, basal cisterns, and sulci were normal and symmetrical. Initial blood tests including autoantibodies and syphilis serology were also negative. On review two days later, his visual acuity was further decreased to 6/24 OD and 6/36 OS. Ishihara testing revealed a significant decrease in color vision, and 4/14 OD and 3/14 OS. Intravenous high-dose methylprednisolone was initiated ( $1 \mathrm{~g}$ daily) for 3 days, followed by oral prednisolone $40 \mathrm{mg}$ daily, tapered by $5 \mathrm{mg}$ weekly.

A lumbar puncture was performed, which revealed a normal opening pressure, helping to exclude papilledema in the presence of findings of bilateral optic nerve swelling. Further analysis of the cerebrospinal fluid found white blood cells and glucose levels to be within normal limits and there was no evidence of microorganisms on microscopy. Red blood cell count was slightly elevated, but in the absence of intracranial hemorrhage on cranial imaging, it is likely that this was secondary to a traumatic tap.

Further blood results revealed a positive result for B. burgdorferi by Lyme enzyme-linked immunosorbent assay and Western blot serology. The patient had no recollection of any recent tick bites but had sustained bites previously. Therefore, the diagnosis of Lyme disease was made in the absence of erythema migrans, because there was a history of exposure to an endemic area, involvement of at least one organ system, and a positive result from the laboratory. ${ }^{4}$ Oral amoxicillin $500 \mathrm{mg}$ twice daily was commenced for 2 months. The medical team was also treating the patient with intravenous ceftriaxone $2 \mathrm{~g}$ twice daily and oral doxycycline for 28 days. His visual acuity gradually improved, reaching $6 / 6 \mathrm{OD}$ and 6/5 OS with full Ishihara in both eyes by late February 2010 (Figure 2). Disc swelling had resolved, resulting in peripapillary thickening and mild pallor of the left disc.

\section{Case report 2}

A 79-year-old gentleman presented in April 2011 with long-standing intermittent blurring of vision in his left eye

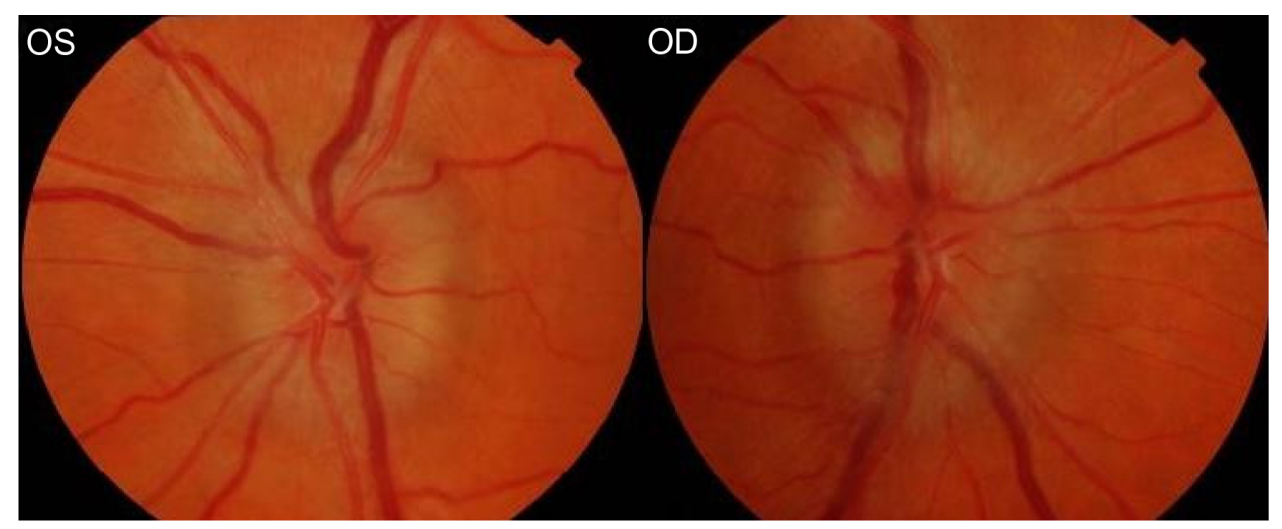

Figure I Optic discs appearance at presentation before treatment commenced, November 2009. 


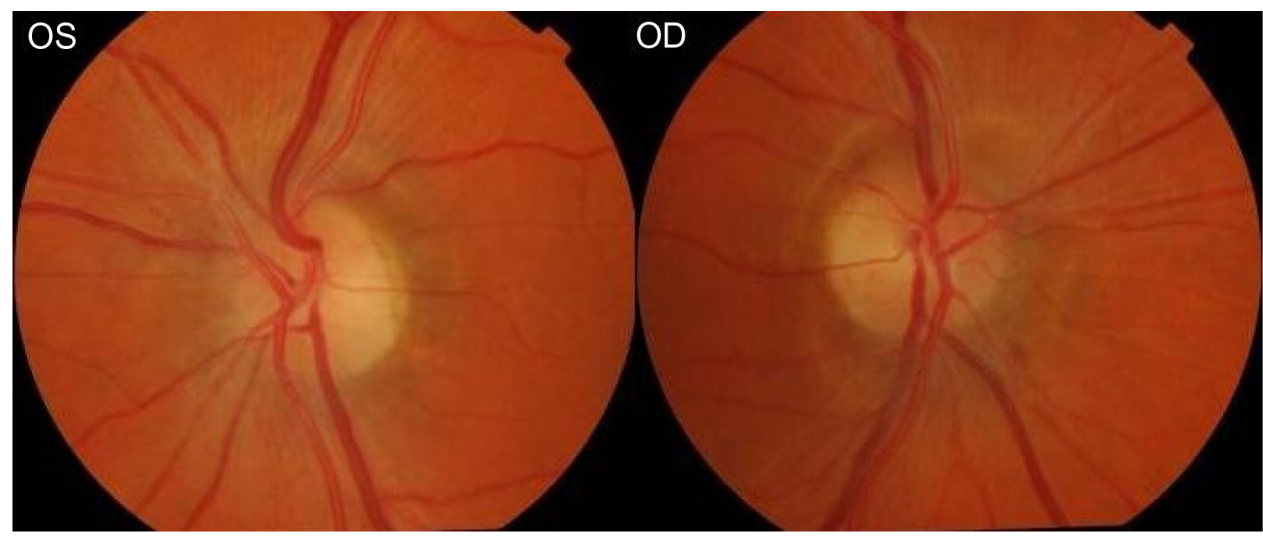

Figure 2 Optic discs appearance after treatment was completed, February 2010.

which had recently transformed into a "gray film" lasting a few minutes, associated with occipital headaches, tiredness, and some intermittent episodes of dizziness. His past ocular history consisted of amblyopia in his right eye, and his past medical history included benign prostatic hyperplasia, duodenal ulcer, squamous cell carcinoma of his left ear, and transient ischemic attacks.

Ocular examination revealed decreased visual acuity of 6/9 OD and 6/6 OS. Dilated fundus examination revealed some peripapillary atrophy of the right disc and a unilateral left optic disc swelling with no overlying or peripheral hemorrhages. Intraocular pressure was $13 \mathrm{mmHg}$ in both eyes. The remainder of the ocular examination and cranial nerve examination did not detect any abnormalities. The possibility of nonarteritic ischemic optic neuropathy was suspected and hence he was admitted by the ophthalmology team for further investigations and followed up one month later with the results.

Hematological (full blood count, urea and electrolytes, glucose, lipid profile, thyroid function tests, C-reactive protein) investigations along with antineutrophil cytoplasmic antibodies, serum angiotensin-converting enzyme, antinuclear antibodies, Venereal Disease Research Laboratory test, Treponema pallidum particle agglutination, Western blot serology, plasma viscosity, chest x-ray, electrocardiogram, computed tomography scan of the head, and magnetic resonance imaging of head were performed. All tests were reported as normal, except from the Western blot serology, which was positive for B. burgdorferi as well as some ischemic changes in the cerebral cortex highlighted by magnetic resonance imaging of brain. No space-occupying lesion was identified. Unfortunately, a successful lumbar puncture was not possible in this case. At his further review, on further questioning, he mentioned that he had worked in the forestry industry previously. He had also sustained tick bites on several occasions, but none in the previous year and had never identified any suspicious new rash.

Therefore, a diagnosis of Lyme-related papillitis was made in the absence of erythema migrans but with a positive history and Western blot serology. He was commenced on intravenous ceftriaxone $2 \mathrm{~g}$ daily for two weeks. On further review, his visual acuity showed evidence of deterioration initially, but after completion of 2 weeks of antibiotic treatment, his visual acuity was restored to back to his normal for both eyes (visual acuity 6/6 OD and 6/6 OS) with full Ishihara in both eyes by late May 2011 and a significant decrease in disc swelling.

\section{Discussion}

The infectious basis for Lyme disease was identified in 1982, making this a relatively recent discovery, which along with its various presenting features, requires a high index of suspicion. There is limited literature available on papillitis as a sole sign of Lyme disease. The most relevant documented cases include a patient identified as suffering with Lyme disease who experienced a severe decrease in visual acuity and subtle bilateral optic nerve swelling, confirmed by angiofluorography. Full vision was recovered following treatment with doxycycline and steroids. ${ }^{6}$ In 1996, an 82-year-old who presented with generalized symptoms of malaise and weight loss, was found to have bilateral optic nerve swelling as the solitary sign of Lyme disease, with a normal opening pressure on lumbar puncture. Enzyme-linked immunosorbent assay and cerebrospinal fluid were both positive for Lyme disease and resolution of his ophthalmic signs were noted following antimicrobial therapy. ${ }^{7}$ The same year, a 71-year-old initially presenting with a monocular papillitis, progressing to a bilateral papillitis several weeks later, 
was diagnosed with Lyme disease following investigative polymerase chain reaction. ${ }^{8}$

A further case of bilateral Lyme papillitis was reported in 1996 in a patient who had been suffering with back pain for a number of months. ${ }^{9}$ Unilateral papillitis was isolated as a clinical manifestation of acute Borrelia infection in 1997. ${ }^{10}$ An additional case of bilateral papillitis was identified in 2000 in a child who had suffered from headaches and visual problems. ${ }^{11}$ A 50-year-old with 10 days of blurred visual acuity and papillitis affecting the left eye was published in 2007. His visual acuity was recorded as $6 / 24$, improving to $6 / 12$ with pinhole. Unfortunately, this did not improve following treatment. ${ }^{12}$ Two additional patients with presumed Lyme disease based on clinical findings but who were seronegative were reported in 2009. This included a 16-year-old male and 38-year-old female with papillitis. The former improved following administration of intravenous methylprednisolone and ceftriaxone. The latter unfortunately experienced further decrease in visual acuity despite intravenous ceftriaxone. This was due to a subsequent finding of a choroidal neovascular membrane. ${ }^{13}$

A case in 2010 emphasized the importance of extensive work-up in cases of neuromyelitis optica. A 40-year-old female patient with lupus erythematosus and GougerotSjogren syndrome developed an afferent pupillary defect and papillitis in the right eye. Four months later, a further finding of optic neuritis affecting the left eye was identified. Within one week of treatment with methylprednisolone, ceftriaxone, and rituximab, a functional improvement was observed. ${ }^{14}$

Here we present two more cases with papillitis as the sole significant ocular sign of Lyme disease. The commonly used laboratory tests for diagnosis of Lyme disease include the enzyme-linked immunosorbent assay and indirect immunofluorescent antibody test. ${ }^{4}$ These detect IgG and IgM specific to B. burgdorferi. Western blot analysis, lymphocyte antigen stimulation, antibody capture enzyme immunoassay, and detection of antibodies in the urine are other potential tests for aiding diagnosis. It should be noted that these tests should only be used in conjunction with clinical information to reach a diagnosis, because signs and symptoms may occur years after the initial bite and $10 \%$ of the population will have a false positive result. ${ }^{4}$

Patients positive for Lyme disease can be treated with antibiotics, including penicillin, tetracyclines, macrolides, and cephalosporins for stages 1 and 2, while more severe cases should receive intravenous penicillin or a cephalosporin. Use of corticosteroids is controversial due to reports of a higher incidence of relapse. Clinical response can take up to a year to occur. ${ }^{15}$

Although Lyme disease is an uncommon cause of papillitis, these two cases underscore the importance of consideration of the diagnosis of Lyme disease with this finding, and that of other vague generalized symptoms such as headache, to ensure the diagnosis is not overlooked. The vague generalized symptoms noted at presentation also highlight the importance of considering Lyme disease when reviewing patients who have had contact with endemic areas. It also demonstrates the importance of thorough investigation, in both confirming a diagnosis and excluding other possible causes for the signs identified. In summary, our two patients reported here highlight the importance of considering Lyme disease as a differential diagnosis in patients presenting with these unusual symptoms or not responding to treatment.

\section{Acknowledgment}

We would like to thank Paul Manson for his guidance and advice regarding the literature research needed for this publication. We would also like to thank Dr Paul Chua for his help in tracking the patients' notes from the Records Department in our absence.

\section{Disclosure}

The authors have no proprietary interests to declare and no funding was received in support of this study.

\section{References}

1. Steere AC, Grodzicki RL, Kornblatt AN, et al. The spirochetal etiology of Lyme disease. N Engl J Med. 1983;308:733-740.

2. Centers for Disease Control and Prevention (CDC) (June 2007). "Lyme disease - United States, 2003-2005". Morbidity and Mortality Weekly Report (Centers for Disease Control and Prevention (CDC); 56(23):573-576.

3. Tsirmpas MD, Tsirmpas D. Lyme disease - a relatively new entity. Oftalmologia. 2006;50:16-20. Romanian.

4. Yanoff M, Duker JS. Ophthalmology. 3rd ed. Edinburgh, UK: Mosby Elsevier; 2009.

5. American Academy of Ophthalmology. Basic and Clinical Science Course 2006-2007. San Francisco, CA: Eurospan Distributors; 2006.

6. Bouat C, Meyer F, Rosier S, et al. Unusual case of bilateral optic neuritis in Lyme neuroborreliosis. Med Trop (Mars). 1995;55:462-465. French.

7. Fedorowski JJ, Hyman C. Optic disk edema as the presenting sign of Lyme disease. Clin Infect Dis. 1996;23:639-640.

8. Kienbacher S, Muhlbauer-Ries E, Schmidt B. Okulare Neuroborreliose - Nachweis Durch Polymerase Chain Reaction. Spektrum der Augenheilkunde. 1996;10(2):80-83.

9. Gerard P, Canaple S, Rosa A. Meningopapillitis disclosing Lyme disease. Rev Neurol (Paris). 1996;152:476-478. French. 
10. Pradella SP, Krause A, Muller A. Acute borrelia infection. Unilateral papillitis as isolated clinical manifestation. Ophthalmologe. 1997; 94:591-594. German.

11. Rothermel H, Hedges TR, Steere AC. Optic neuropathy in children with Lyme disease. Pediatrics. 2001;108:477-481.

12. Mishra SK, Murjaneh S, Morgan MS, et al. Papillitis, Lyme disease, and cats. Eye. 2007;21:850-851

13. Amer R, Brannan S, Forrester JV. Inflammatory choroidal neovascular membrane in presumed ocular Lyme borreliosis. Acta Ophthalmol. 2009;87:346-348.
14. Garcia T, Servettaz A, Maarouf A, et al. Devic's syndrome associated with lupus erythematosus, Gougerot-Sjogren and Lyme disease. Presented at the 18th International Neuro-Ophthalmology Conference, Lyon, France; June 15-18, 2010.

15. Winterkorn JM. Lyme disease: neurologic and ophthalmic manifestations. Surv Ophthalmol. 1990;35:191-204.

\section{Publish your work in this journal}

Clinical Ophthalmology is an international, peer-reviewed journal covering all subspecialties within ophthalmology. Key topics include: Optometry; Visual science; Pharmacology and drug therapy in eye diseases; Basic Sciences; Primary and Secondary eye care; Patien Safety and Quality of Care Improvements. This journal is indexed on

Submit your manuscript here: http://www.dovepress.com/clinical-ophthalmology-journal

\section{Dovepress}

PubMed Central and CAS, and is the official journal of The Society of Clinical Ophthalmology (SCO). The manuscript management system is completely online and includes a very quick and fair peer-review system, which is all easy to use. Visit http://www.dovepress.com/ testimonials.php to read real quotes from published authors. 